\title{
MEASURES OF TRADE OPENNESS USING CGE ANALYSIS
}

\author{
by \\ P. J. Lloyd \\ and \\ D. MacLaren \\ University of Melbourne
}

Revised

May 2000

Accepted for publication in the Journal of Policy Modeling (forthcoming)

JEL Classification: B41, C68, F13, F14

Address:

Department of Economics

The University of Melbourne

Victoria 3010

Australia

Fax: (61) 383446899

Tel: (61) 383445291

Email: p.lloyd@ecomfac.unimelb.edu.au 


\title{
MEASURES OF TRADE OPENNESS USING CGE ANALYSIS
}

\begin{abstract}
Using a cge model of the world economy, a group of measures of trade openness are derived which lie on the unit interval and have a welfare interpretation. They are transformations of the Uniform Tariff Equivalent and have the property that national welfare increases monotonically with the measure of openness. An alternative measure is the ratio of the volume of trade in a restricted trade situation to that under the free trade situation. These measures are calculated for 14 regions of the world economy, using the GTAP model. We find close correspondence between all the cge measures but the ranking of countries according to these measures differs substantially from that of the actual trade ratios.
\end{abstract}




\section{MEASURES OF TRADE OPENNESS USING CGE ANALYSIS}

\section{Existing Measures of Openness}

Measures of openness have long been of interest to international economists because of the debate about protection and the level of national output or national welfare. This interest has been renewed with the development of New Growth Theory which posits a relationship between openness and the rate of growth of national output (see Edwards, 1993, Harrison, 1995 and Pritchett, 1996). But empirical studies of these relationships have been hampered by the absence of a suitable theoretically-derived measure of openness.

The common measure is the ratio of actual exports plus imports to GNP or GDP. One difficulty with this measure is that the figures in the numerator and denominator are in current prices. Over time the prices of goods and services traded internationally and those of goods and services produced domestically may diverge because of changes in the exchange rate or other relative price movements. A second and more substantial problem is that this measure of openness depends on two quite distinct sets of factors: one set is the resource endowments, country size, tastes, technology and other determinants of comparative advantage and the other set is the levels of trade restrictions. The former are non-policy variables whereas the latter are policy variables. A country may have a high trade ratio because it is small or has resources which are valuable to other countries or perhaps because its residents have a preference for foreign goods rather than because it has low restrictions on trade with other countries.

Some attempts have been made to separate these two sets of factors. One approach is to use deviations of actual from predicted trade ratios. A model can be used to predict the pattern and volume of trade and then to compare the actual and the predicted trade ratios (Leamer, 1988). The model could be a gravity type model which used variables such as country size and distance or a theoretical trade model. This approach does not use trade policy variables as explanators of trade patterns or deviations from the predicted pattern.

It is the level of trade restrictions which is the concern of policymakers and analysts. The appropriate approach is to construct some measure which is an average of the levels of trade restrictions on different traded commodities. But there is a fundamental obstacle to constructing summary statistics of the average level of trade restrictions in an economy. There has long been argument among trade theorists about the appropriate weights to attach to the level of trade restrictions in each industry group. This is an index number problem.

Section II presents alternative indices which use computable general equilibrium (cge) analysis. The cge model used is the GTAP model of the world economy. Cge analysis has the advantage that it captures economy-wide effects of changing restrictions on trade. Section III reports calculations of these indices. Some conclusions are reported in Section IV. 


\section{Measures of Openness Using $C G E$ Analysis}

The problem of calculating an average of differentiated levels of assistance is a particularly difficult index number problem. We require a scalar index which aggregates the levels of assistance to the producers of all commodities. It is an index number for the whole economy and one set in a general equilibrium context.

The first issue that must be resolved is the purpose of the index as the choice of index will depend upon the purpose. If the index is to provide a measure of the costs of protection, it will be necessary to specify that it is intended to measure the production costs of the distortions or the total cost to the consumers and producers of the economy or some other variable. For this purpose, most of the debate has been about the welfare costs of protection to the economy. Consequently, the logical choice is a measure which indexes the welfare costs to the economy of a differentiated structure of assistance.

The obvious measure of policy openness in this welfare context is the "Uniform Tariff Equivalent" of the Trade Restrictiveness Index (UTE). This is the uniform tariff rate which yields the same utility vector as the set of differentiated tariff rates which exist in reality. This measure was developed by Anderson and Neary $(1994,1996)$ for small economies. (See also Anderson, 1995 and 1998). It provides an average measure of trade restrictions for an economy.

The Uniform Tariff Equivalent is derived from the Trade Expenditure Function for a small distorted economy first developed by Lloyd and Schweinberger (1988). The function is

$$
B\left(p^{*}, p, v, u\right)=e(p, u)-g(p, v)-\left(p-p^{*}\right) m
$$

where $p^{*}$ and $p$ are the vectors of world prices and domestic prices respectively, $v$ is the vector of primary endowments which is assumed constant and $u$ is the vector of household utilities. $e(p, u)$ is the national expenditure function and $g(p, v)$ is the national product function. $m$ is the vector of imports/exports and $\left(p-p^{*}\right) m$ is the aggregate revenue collected from the tariffs. The trade expenditure function measures the aggregate value of transfers to the households of the economy which is required to sustain a given utility vector, given the factor income received by the households from production and the net tax revenues which are assumed to be returned to the households.

For our purposes, it is convenient to eliminate domestic prices from the function. If trade restrictions are expressed as ad valorem or ad valorem equivalent rates, the relationship between domestic and international prices in industry $i$ is given by the equation

$$
p_{i}=p_{i}^{*}\left(1+t_{i}\right), \quad i=1, \ldots, n
$$


where $p_{i}$ and $p_{i}^{*}$ are the domestic and international prices, and $t_{i}$ is the ad valorem tariff rate on the products of the industry $i$. Using Equation (2), we can then rewrite the trade expenditure function as $B\left(p^{*}, t, v, u\right)$ where $t$ is the vector of differentiated tariff rates for the $\mathrm{n}$ goods, $\left(t_{1}, \ldots t_{n}\right)$. We denote the Uniform Tariff Equivalent by the symbol $T . T$ is then given from the equation

$$
B\left(p^{*}, t, v, u\right)=B\left(p^{*}, \mathrm{~T} \mathbf{1}, v, u\right)
$$

where 1 is the unit vector and $T \mathbf{1}$ is the vector of uniform rates $(T, \ldots, T)$. That is, $T$ is the uniform tariff which yields the same national utility vector as the differentiated structure of tariffs. It is an index of the average level of restrictions. The transfer from the rest of the world to the economy, the deficit/surplus on the current account of the balance of payments, is held constant between situations. This index captures all of the general equilibrium demand and supply responses to changes in the structure of border interventions through the changes in $e(p, u)$ and $g(p, v)$. Differentiating Equation (3) totally and setting this differential equal to that with a uniform tariff, gives the Uniform Tariff Equivalent.

This simple but ingenious concept solves the index number problem in calculating an average measure of trade restrictions. $T$ is a true utility-constant index of the restrictions. It uses the same idea of constant utility that underlies the true indexes of the cost of living for households. ${ }^{\square}$ It will exist unless the differentiated structure of tariffs approaches that given by the utility-maximizing "optimal tariff".

It has the desirable property that, for a given economy, a decrease in the index must increase the welfare of the economy in the sense of a Pareto improvement. By derivation, the Uniform Tariff Equivalent is a weighted average of the individual commodity tariff rates (see Anderson and Neary, 1994, Equation (6)).

$$
\tau=\sum_{i}^{n} t_{i} w_{i}, \text { where } w_{i}=\left(\partial B / \partial p_{i} \cdot p_{i}\right) / \sum\left(\partial B / \partial p_{i} \cdot p_{i}\right) \text { and } \sum_{i}^{n} w_{i}=1
$$

The weights $\left(w_{i}\right)$ are the effects of the tariffs on welfare in the distorted trade situation compared to the free trade situation. These welfare weights depend in turn on the changes in imports, not the values of trade in the free trade or the distorted trade situations. The use of welfare weights makes the measure of ayerage tariffs responsive to the peak tariff rates which have a high marginal welfare loss.

In the GTAP model used in the next section to estimate measures of openness, all countries are large, not small. That is, they each have some influence on the international prices because of their sales and purchases. Uniform Tariff Equivalents will be calculated from the model by simulation. Nevertheless, it is desirable to have an appreciation of the determinants of Uniform Tariff Equivalents when countries are large. In this case the international prices are determined by the requirement in general equilibrium that the vector of world excess demand functions be non-positive: 


$$
m(p, v, u)+m^{*}\left(p^{*}, v^{*}, u^{*}\right) \leq 0
$$

Equations (1), (2) and (5) form a system of equations which determine the transfer and the international prices, given the national tariff vectors, national endowments and utility vectors.

Differentiating Equation (1) with respect to both domestic and international prices and setting this differential equal to that with a uniform tariff, gives the Uniform Tariff Equivalent for a large economy. For a large country, this has the form

$$
\begin{aligned}
& T=\sum_{i}^{n} t_{i} v_{i}+\sum_{i}^{n} t_{i} u_{i} \\
& \text { where } v_{i}=\left(\partial B / \partial p_{i} \cdot p_{i}\right) / \sum\left(\partial B / \partial p_{i} \cdot p_{i}+\partial B / \partial p_{i}^{*} \cdot p_{i}^{*}\right) \\
& \qquad u_{i}=\left(\partial B / \partial p_{i}^{*} \cdot p_{i}^{*}\right) / \sum\left(\partial B / \partial p_{i} \cdot p_{i}+\partial B / \partial p_{i}^{*} \cdot p_{i}^{*}\right) \text { and } \\
& \\
& \sum_{i}^{n}\left(v_{i}+u_{i}\right)=1 .
\end{aligned}
$$

The changes in the domestic prices $\left(d p_{i} / p_{i}\right)$ due to tariffs will induce changes in foreign prices $\left(d p_{i}^{*} / p_{i}^{*}\right)$. The latter set of changes in international prices can be derived from Equation (5). Thus, the Uniform Tariff Equivalent for a large economy differs from that for a small economy in that it has an extra term reflecting the changes in the terms of trade when a uniform rate replaces a differentiated structure of tariff rates. This terms of trade term may be positive or negative. It might be expected to be small in most cases as, unlike the situation in the optimal tariff literature, the utility of the nation whose average tariff is being measured is unchanged. As the country becomes small, the terms of trade term vanishes.

This calculation gives us the index of the average tariff, $T$, but one problem remains. In general the index $T$ decreases as trade becomes more open and it ranges from 0 to plus infinity whereas we want an index of openness which increases as import restrictions are decreased. It is desirable to measure openness on the continuum of the closed interval $[0,1]$. The end points are well defined. 0 is the point of no interdependence between the national economy and the rest of the world, that is, the national economy is closed. Hence, the markets in the country clear independently and there is for each commodity a set of distinct national prices. 1 is the point of "complete" openness with no restrictions of international trade. The Law of One Price holds for the world economy in this situation. Any point on the open interval $(0,1)$ away from the end points represents some openness of its national economy but less than complete openness or complete integration with the rest of the world.

Several measures which have these properties can be obtained by taking transformations of $T$. One is the following measure:

$$
L=1-(T / \bar{T})
$$


$T$ is the Uniform Tariff Equivalent and $\bar{T}$ is the level of the uniform tariff rate which would eliminate international trade with other countries, the prohibitive uniform tariff level. $\bar{T}$ is the maximum value of $T$ in the hypothetical situation in which all trade ceases. By construction, $L \in[0,1]$. It is 0 when there is no international trade and 1 when there is completely free trade, that is, no border tax distortions in any market of the national economy. It is a true index which indexes utility in the sense that national welfare increases as the economy becomes more open because national welfare decreases with $T$.

Another possible transformation is:

$$
M=1 /(1+T)^{\lambda}, \text { where } \lambda>0
$$

$M \in[0,1]:$ it is 0 when there is no international trade and 1 when there is completely free trade, and it decreases monotonically with $T$. This is also a true index. If $\lambda=2, T$ captures the Harberger effect, namely that the welfare loss of a tariff increases with the square of the tariff rate. Compared to the transformation $1 /(1+T)$ with $\lambda=1$, which also has the desired distribution on the unit interval, the use of the second power makes the measure move up and down the unit interval more rapidly as $T$ varies.

A third measure is:

$$
N=Q / \tilde{Q}
$$

$Q$ is the index of the volume of trade in the current situation and $\widetilde{Q}$ is the index of the volume of trade in the (hypothetical) free trade situation. As the volume of trade in a restricted trade situation is lower than in the free trade situation, $N \in[0,1]$. Again, it is 0 when there is no international trade and 1 when there is completely free trade. This measure is appropriate when one is interested in the extent to which the volume of trade has been restricted.

Ideally, the chosen measure of openness should apply to trade in services as well as trade in goods. In practice at the present time the measure will have to be restricted to trade in goods as there are no measures of restrictions on trade in services. Moreover, trade in some services is linked to trade in factors. One could also, if desired, compute an index of openness for a subset of traded goods, say manufactures, or for individual industries in the same manner.

\section{Estimation of the Measures for Regions in the GTAP Model}

Our approach is to use a cge model to calculate the measures of openness. Cge models capture the important general equilibrium effects of trade restrictions. They have an advantage over the statistical models that attempt to estimate a model which replicates 
trade patterns, such as that used by Leamer (1988). Of course, the credibility of the measures depends on the adequacy of the cge representation of the actual economy.

The Global Trade Analysis Project model (GTAP) (version 4) is used as it has a number of countries or "regions" for which measures of openness can be calculated. GTAP has 45 regions, 5 factors and 50 commodities (sectors). In our application, these regions and commodities are aggregated into 14 regions and 10 commodities and the factors into 3. The regions are CER (Australia and New Zealand), NAFTA (Canada, Mexico and the United Sates), Japan, the European Union, Korea, Singapore, Taiwan, Hong Kong, Indonesia, Malaysia, the Philippines, Thailand, China, Vietnam and ROW (the rest of the world). The commodities are agriculture (Agri), natural resources (Nat_res), food (Food), textiles (Textiles), clothing (Clothing), light manufactures (L_Manuf), heavy manufactures (H_Manuf), transport, machinery and equipment (T_M_E), utilities and services. The database relates to 1995 , with values in 1995 \$US but for a variety of years.

The levels of restrictions of bilateral imports, across all 14 regions and 10 commodities, were expressed as average tariff rates, derived from the ratio of the value of imports at domestic prices to their value at international market prices. Those relating to each region's imports from ROW are shown in Table 1. It should be noted that the vector of differentiated tariff rates varies across import sources and the rates from ROW should not necessarily be taken as indicative. For example, the tariff rates on imports by Japan of agricultural products from CER is 129 per cent and from NAFTA is 208 per cent compared with 4.3 per cent and 7.8 per cent, respectively, from ROW. For any given importing region, there are wide variations in the tariff rates across commodities. As shown in the Table, in each case, imports are restricted rather than subsidized, tariff rates being positive, as would be expected. These data illustrate the differentiated (implicit) tariff structures which exist within and between the regions. These data also illustrate the relative success which the GATT had in reducing tariffs on manufactured goods, and the lack of success in achieving reductions in agriculture and in textiles and clothing.

For each region $(r)$ independently, the initial task is to calculate the Uniform Tariff Equivalent of the current differentiated tariff structure. In order to fix the balance of trade, as required by Equation (1), the variables $d b a l(r)$ and the utility of the government household $u g(r)$ were made exogenous when region $r$ altered its tariffs. $T$ is estimated by first choosing a uniform rate within the range of the minimum and maximum rates that might be approximately utility-constant, i.e., the percentage change in private household per capita utility ( $u p$ ) is zero with respect to the differentiated tariff base. If the net transfer to the economy with this rate exceeds (falls short of) the constraint in Equation (2), the uniform rate is increased (or decreased) until the constraint is satisfied.

The second simulation applied the tariff shocks for trade flows by region and commodity to generate the free trade equilibrium for that region. This simulation provided new values for the endogenous variables in the model. For the purposes of this paper, the only variables of interest are those relating to utility, to the terms of trade and to the volumes of imports and exports. The simulation provides the necessary information from which to 
calculate the index $N$. Third, to obtain an estimate of the index $L$, it was necessary to shock the free trade equilibrium with progressively higher levels of a uniform tariff (from 0 per cent to 100 per cent) in order to estimate $T$ (the uniform tariff equivalent) and, eventually, to obtain $\bar{T}$. This is referred to as the Uniform Tariff Rate to distinguish it from the Uniform Tariff Equivalent of the actual differentiated tariff structure. (Hence, the Uniform Tariff Equivalent is that particular value of the Uniform Tariff Rate which yields the utility vector of the base situation.) For each of the variables reported in Figures 1,2 and 3, the value under a particular level of the Uniform Tariff Rate is expressed as a percentage change from the value in the free trade situation.

Consider the percentage change in the per capita utility of the household sector relative to the free trade situation shown in Figure 1 for CER, NAFTA, Japan and Malaysia. This is the variable up. Starting from the free trade situation, this function for CER and Malaysia rises above zero and then begins to flatten off but not reaching a maximum value for uniform tariff rates in the range zero per cent to 100 per cent. By contrast, for NAFTA and Japan the function reaches a maximum and then begins to decline. This shows that for these latter two regions, there is an optimal uniform tariff which maximizes the value of private household per capita utility. In this example, it is around 40 per cent for NAFTA and 80 per cent for Japan. The optimal private household per capita utility is around 1.28 per cent higher than the free trade level for NAFTA and 2.99 per cent for Japan. Note that the optimum uniform rate is not the optimal structure of differentiated rates, according to Optimal Tariff theory, which would produce a higher level of utility.

Economic theory gives us little guidance to the shape of utility or the change in utility as a function of tariff levels. We are particularly interested in the slope of the function as the Uniform Tariff Rate approaches $\bar{T}$. One might expect that there would be diminishing returns to opening trade. As a completely closed economy is opened up a little, there may be some commodities which are simply not producible in a country and for which the gains in utility from obtaining them from international trade would be very large; for example, medical drugs or some kinds of producer goods. As the quantities of goods traded increase, the additional returns in terms of marginal utility might diminish. However, the graphs in Figure 1, except for Malaysia, show little variation in the changein-utility function as the uniform tariff is reduced from 100 per cent. It would require simulating much higher uniform tariff rates to determine whether the intuition explained above is consistent with this model.

The graphs in Figure 2 show that the volume of imports (and exports not shown) contract for each region but to different degrees. For NAFTA, the contraction is smallest with the function become almost horizontal once the uniform tariff rate reaches 80 per cent, the percentage reduction in the volume of imports being of the order of 17.5 per cent. A similar pattern emerges for the other regions. The effects on the terms of trade of applying a uniform tariff causes an improvement for each region as the uniform rate is increased towards 100 per cent (Figure 3). The graphs are similar in shape but different in slope at any non-zero rate of uniform tariff. 
Now consider the calculation of the measure of policy openness, $L$. This requires obtaining the prohibitive level of the Uniform Tariff Rate. One would expect that, for every economy, there would be some value of the uniform tariff rate at which trade ceases, albeit possibly a very high rate. There is, however, a fundamental difficulty in obtaining $\bar{T}$ in the GTAP model. Inspection of Figure 2 for the four selected regions shows that the index of the volume of imports declines slowly and the percentage change function is convex from below. There is no sign of convergence to zero trade for uniform tariff rates at the 100 per cent level. Other simulations show that substantial levels of trade persist when the uniform rate is increased to well in excess of 100 per cent. Similarly, there is no sign that the utility series converge to a minimum level as the uniform tariff rate is increased. Hence, $\bar{T}$ does not exist.

The reason for the non-existence of $\bar{T}$, and hence $L$, lies in the Armington specification of the relationships between domestic and imported goods in the GTAP model (Hertel, 1997, chapter 2). In this specification, the outputs of an industry by different nations (or regions) are regarded as nationally-differentiated imperfect substitutes. Goods imported into one country are purchased by producers as intermediate inputs or capital goods or by consumers as final consumer goods. Demand for both imported intermediate inputs and imported consumer goods is determined by a multi-level function. At the bottom level of the production function, demand in one industry for quantities of a composite import intermediate good and a nationally-produced good is given by a CES function. Moreover, the quantity of the composite import good is itself a CES function of the supplies from all foreign country sources. At the bottom level of the utility function, the quantities of the tradable consumable commodities are CES functions of the domestic and the imported goods.

This specification has the considerable advantages that it provides an explanation of cross-hauling of similar products (intra-industry trade) and of the pattern of bilateral flows between regions in the model (Hertel, 1997, p. 41), and it is convenient and parsimonious for the parameterization of the demand functions in the cge model. However, the Armington assumptions have major incidental consequences for other endogenous variables in the model. Many commentators have noted the strength of terms of trade effects in models that use the Armington assumptions (see, for example, Brown, 1987 and Shiells and Reinert, 1993). The strength of the terms of trade effect is due to the assumption of nationally differentiated goods together with the property of the CES function that all inputs are econgmically essential because all must be used unless the

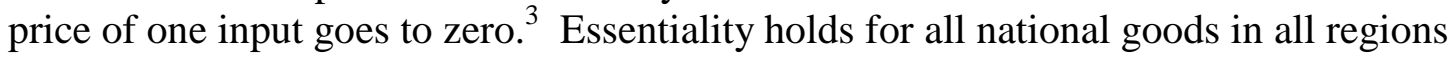
and for all prices in the model.

There are two notable features of the terms of trade effects. First, the terms of trade continue to improve as the uniform rates are increased to 100 per cent and higher. The functions plotted for CER, NAFTA, Japan and Malaysia are all approximately linear (Figure 3 ) and the improvements of the terms of trade show no sign of diminishing as the uniform rate is increased further. Second, the terms of trade effects are strong for all countries, not merely for large countries which account for a large share of market sales or purchases, as in standard trade models with homogeneous goods. Both of these 
features are quite implausible. While the CES specification has great advantages, it has very substantial disadvantages in the lack of realism it produces in these respects.

The combination of the Armington specification of national goods and the adoption of the CES function to model the demand relationships between these national goods has one further consequence in the present context. It means that there is no level of trade restrictions which will eliminate trade. This is the reason why $L$ does not exist.

Since the measure $L$ (Equation (7)) is not available, we report $T$ and its transformation, $M$ (Equation (8)), in Table 2. In terms of the Uniform Tariff Equivalent, Hong Kong (0 per cent) ranks first as the most open followed by Singapore ( 0.8 per cent) NAFTA ( 2.8 per cent) and the EU (3.8 per cent). The next five regions still have a value of $T$ below 10 per cent, namely, Korea (5.9 per cent), Taiwan (6.7 per cent), Indonesia (7.3 per cent), CER (8.3 per cent) and Malaysia ( 9.8 per cent). The remaining four countries are more dispersed: Vietnam (12.1 per cent), Thailand (15.4 per cent), China (20.2 per cent), and the Philippines (23.5 per cent). In the case of Japan, there was no uniform tariff rate in the range of 0 per cent to 200 per cent which generated the same utility as the differentiated tariff equilibrium.

The measure of openness given by $M$ is reported in Table 2 for the values of $\lambda=1$ and 2 . These are labeled $M_{1}$ and $M_{2}$ respectively. By construction, these measures must rank countries in the same order as the uniform tariff equivalent and the order is not changed by varying $\lambda$.

We also calculate the measure $N$. The measure $N$ is obtained by taking the limit in the direction of complete openness rather than the limit in the direction of zero openness, as with $L$. It therefore avoids the problem of the non-existence of $\bar{T}$ and provides another alternative measure.

The results for the measure of openness defined by $N$ are shown in Table 2. These results were obtained for each region from the free-trade simulation by applying the percentage change in the quantity of all exports (qxwreg $(r)$ ) and the quantity of all imports (qiwreg $(r))$ to their respective values in the differentiated tariff base situation. According to this definition of openness, Hong Kong ranks first as the most open (1.00), followed by Singapore (0.99), the European Union (0.98) and NAFTA (0.97) (Table 2). A further five regions have values in nineties. These are Indonesia (0.93), CER (0.93), Taiwan (0.92), Japan (0.90) and Malaysia (0.90). In the eighties are Korea (0.89), Thailand (0.87) and Vietnam (0.84). The remaining two are China (0.70) and the Philippines (0.68). With the exception of the last two countries, the values are all remarkably high, showing that the present level of trade restrictions does not reduce the volume of trade much below that which would prevail under free trade policies in each region.

It should be noted that the specification of trade restrictions in the model understates the level of restrictions in several ways. In particular, the assumption of a single (uniform) rate for the industries omits the intra-industry variation of rates on individual commodities within the industries and the use of tariff equivalents for the non-tariff 
barriers (ntbs) understates the restrictiveness of many ntbs because of their nontransparency, rent generation and restrictions on competition. In addition, the measures of openness calculated from the GTAP model reflect the degree of completeness in the protection database. For some countries, completeness will be greater than in others. Thus the understatement of the levels of restrictions may also reduce the inter-country variation in the measured levels of openness.

Finally, in Table 2 we report the ratio of actual exports plus imports to GDP (measure $A$ ), the common measure of openness, for the regions. These ratios relate to the base situation with the actual differentiated tariff structures. The rankings now appear to be quite different. Apart from Hong Kong and Singapore which retain top ranking, although reversed from measures $T$ and $N$, the third-ranked country is now Malaysia (160.9 per cent), followed by Vietnam (112.4 per cent) and the Philippines (102.8 per cent). NAFTA and the EU, which rank high on the $c$ ge measures, now rank low at 27.9 per cent and 54.9 per cent, respectively.

\section{Conclusions}

These results show that cge analysis can be used to calculate general equilibrium measures of openness. We have calculated the Uniform Tariff Equivalent (T), and the measures $M$ and $N$ for the regions in the model. It proved impossible to calculate the measure $L$ as no prohibitive Uniform Tariff Equivalent exists in a model with the Armington assumption and CES functions.

The transformations of $T$ are the preferred measures when one is interested in a measure of trade policy stance. Most of the regions in the GTAP model are remarkably open in terms of these measures. The measure $N$, which expresses the actual trade volumes as a percentage of the free trade volumes, is the appropriate measure when one is interested in the effects of trade policy on the volume of trade.

There is a close correspondence between the rankings based on the Uniform Tariff Rate ( $T$, and the two transformations $M_{1}$ and $M_{2}$ ) on the one hand and the ranking according to the volume of trade, $N$, on the other. However, the ranking of actual trade ratios, the measure used in most empirical studies, differs notably from the $c g e$ measure rankings in most cases. Because the cge measures reflect differences in the policy stances of the regions, they are to be preferred to the actual ratios which combine both policy and nonpolicy variables.

\section{Endnotes}

* We are grateful to Simon Evenett, Tom Hertel and Will Martin for their comments and to the participants of the Economics Workshop at the University of Melbourne for their helpful suggestions on an earlier draft and especially to David Harris who suggested taking transformations of T other than the transformation L. 
${ }^{1}$ If one wished to measure only the loss of national output through the distortion of prices to producers, one could define a uniform tax equivalent using the national product function in place of the trade expenditure function used in Equation (2). This would be $g\left(p^{*}, \tau, v\right)=g\left(p^{*}, S \mathbf{1}, v\right)$ where $\tau$ is the vector of distortions of producer prices in ad valorem terms and $S \mathbf{1}=(S, \ldots, S)$ is the vector of uniform distortions of producer prices. This would provide a GNP-constant measure of average production distortions.

2 One case, in which the import functions are linear functions of own prices only, provides a useful illustration of the properties of T. In this special case, the Uniform Tariff Equivalent reduces to (Feenstra, 1995, p. 1562):

$$
T=\left[\sum_{i}^{n} t_{i}^{2} w_{i}\right]^{1 / 2}, \text { where } w_{i}=\left(p_{i}^{* 2} \partial m_{i} / \partial p_{i}\right) / \sum\left(p_{i}^{* 2} \partial m_{i} / \partial p_{i}\right) .
$$

As an index this function has two important properties. First, the weights are proportional to the shares in the changes in the value of imports induced by the tariffs. Hence, prohibitive tariff rates are included. Secondly, the index is the mean of order 2, not the arithmetic mean. Tariff rates enter to the second power. This reflects the Harberger Triangle effect: the welfare loss due to a tariff increases with the square of the tariff rate because a tariff rate has both a price effect and a quantity effect, with the latter also proportional to the price effect.

The index is the root mean square, the square root of the mean of the weighted squared tariff rates. The mean square is the sum of the (weighted) mean and the (weighted) variance of the tariff rates. This shows that the welfare cost of distortions is an increasing function of the mean and the variance of the individual rates. Anderson (1995) gives a more complex expression for the general case with cross-price effects.

${ }^{3}$ Consider a CES production function of two inputs. For values of the elasticity of substitution less than unity, the isoquants approach asymptotes in the interior of the input space. This means that both inputs are essential in that output is zero if the quantity used of either input is zero (Shephard, 1970, chapter 2). For values of the elasticity of substitution greater than unity, the isoquants intersect the axes. This indicates that strictly positive quantities of the output can be produced with a zero quantity of one input but even then the intersection is a point of tangency at which the slope is zero or infinite. This property was noted by Chipman (1965, p. 59). The same property holds for the CES sub-utility functions which require that the imported and domestic goods must be consumed in strictly positive quantities for any set of prices excluding zero. At the lowest levels of the function at which the imports from multiple regions are combined in a CES function, the imports from every region are essential. 



\section{REFERENCES}

Anderson, J. E. (1995) Tariff Index Theory. Review of International Economics 3:156-73.

Anderson, J. E. (1998) Trade Restrictiveness Benchmarks. Economic Journal 108:11111125 .

Anderson, J. E. and Neary, P. J. (1994) Measuring the Restrictiveness of Trade Policy. The World Bank Economic Review 8:151-169.

Anderson, J. E. and Neary, P. J. (1996) A New Approach to Evaluating Trade Policy. Review of Economic Studies 63:107-125.

Brown, D. K. (1987) Tariffs, Terms of Trade and National Product Differentiation. Journal of Policy Modeling 9:503-526.

Chipman, J. (1966) A Survey of the Theory of International Trade: Part 3, the Modern Theory. Econometrica 34:18- 76.

Edwards, S. (1993) Openness, Trade Liberalization and Growth in Developing Countries. Journal of Economic Literature 31:1358-93.

Feenstra, R. C. (1995) Estimating the Effects of Trade Policy, in Handbook of International Economics Vol. III, Grossman, G. N and Rogoff, K. (eds), Amsterdam: North Holland.

Harrison, A. (1995) Openness and Growth. National Bureau of Economic Research Research Paper No. 5221.

Hertel, T. (ed.) (1997), Global Trade Analysis: Modeling and Applications. Cambridge, UK: Cambridge University Press.

Leamer, E. E. (1988) Measures of Openness, in Trade Policy Issues and Empirical Analysis, R. E. Baldwin (ed.). Chicago: University of Chicago Press.

Lloyd, P. J. and Schweinberger, A. G. (1988) Trade Expenditure Functions and Gains from Trade. Journal of International Economics 24:275-297.

Pritchett, L. (1996) Measuring Outward Orientation in LDCs: Can it be Done? Journal of Development Economics 49:307-335.

Shiells, C. R. and Reinert, K. A. (1993) Armington Models and Terms of Trade Effects: Some Econometric Evidence for North America. Canadian Journal of Economics 26:299-316. 
Table 1: Tariff Rates (\%) on Imports from ROW by Regions

\begin{tabular}{lrrrrrrrr}
\hline & \multicolumn{7}{c}{ Regions } \\
\cline { 2 - 8 } Sector & CER NAFTA & Japan & EU & Korea S'pore & Taiwan & H. K. \\
\hline 1 Agric & 4.3 & 7.8 & 27.3 & 12.0 & 23.1 & 21.2 & 13.1 & 0 \\
2 Nat_Res & 0.1 & 0.9 & 0.2 & 0.1 & 4.8 & 0.0 & 6.8 & 0 \\
3 Food & 5.6 & 11.1 & 16.4 & 17.5 & 20.0 & 14.8 & 19.3 & 0 \\
4 Textiles & 14.8 & 8.3 & 3.2 & 4.5 & 6.4 & 0.1 & 6.2 & 0 \\
5 Clothing & 6.1 & 13.0 & 9.6 & 9.7 & 8.0 & 4.8 & 12.3 & 0 \\
6 L_Manuf & 11.6 & 3.1 & 3.0 & 7.1 & 5.5 & 0.2 & 3.5 & 0 \\
7 H_Manuf & 5.1 & 2.6 & 1.6 & 2.1 & 5.2 & 1.7 & 3.8 & 0 \\
8 T_M_E & 8.5 & 2.1 & 0.1 & 2.0 & 6.3 & 0.7 & 6.9 & 0 \\
9 Utilities & 0.0 & 0.0 & 0.0 & 0.0 & 0.0 & 0.0 & 0.0 & 0 \\
10 Services & 0.3 & 0.0 & 3.2 & 0.0 & 0.0 & 0.0 & 0.0 & 0 \\
\hline \hline
\end{tabular}

Regions

\begin{tabular}{lrrrrrr} 
Sector & Indonesia & Malaysia & Philippines & Thailand & China & Vietnam \\
\hline 1 Agric & 3.6 & 64.9 & 16.6 & 29.9 & 10.3 & 5.7 \\
2 Nat_Res & 2.7 & 3.6 & 0.2 & 3.1 & 3.5 & 1.0 \\
3 Food & 2.4 & 10.3 & 26.5 & 47.6 & 19.7 & 29.1 \\
4 Textiles & 5.5 & 12.9 & 22.3 & 16.4 & 24.4 & 23.5 \\
5 Clothing & 27.2 & 20.7 & 29.7 & 40.8 & 68.3 & 42.3 \\
6 L_Manuf & 5.2 & 21.6 & 36.2 & 11.8 & 24.2 & 9.2 \\
7 H_Manuf & 4.9 & 4.3 & 17.8 & 8.4 & 8.6 & 7.3 \\
8 T_M_E & 5.2 & 4.4 & 25.9 & 10.8 & 25.5 & 6.1 \\
9 Utilities & 0.0 & 0.0 & 0.0 & 0.0 & 0.0 & 0.0 \\
10 Services & 0.0 & 0.0 & 0.0 & 0.0 & 1.7 & 0.0 \\
& & & & & & \\
\hline \hline
\end{tabular}

Source: GTAP database version 4 
Table 2: Alternative Measures of Openness*

\begin{tabular}{lrrrrrrrrrr}
\hline \hline \multicolumn{1}{c}{ Region } & \multicolumn{1}{c}{$A$} & Rank & \multicolumn{1}{c}{$T$} & Rank & \multicolumn{1}{c}{$M_{1}$} & Rank & $M_{2}$ & Rank & $N$ & Rank \\
\hline CER & 42.6 & $(12)$ & 8.3 & $(8)$ & 0.92 & $(8)$ & 0.85 & $(8)$ & 0.93 & $(6)$ \\
NAFTA & 27.9 & $(13)$ & 2.8 & $(3)$ & 0.97 & $(3)$ & 0.95 & $(3)$ & 0.97 & $(4)$ \\
Japan & 16.7 & $(14)$ & na & & na & & na & & 0.90 & $(9)$ \\
EU & 54.9 & $(9)$ & 3.8 & $(4)$ & 0.96 & $(4)$ & 0.93 & $(4)$ & 0.98 & $(3)$ \\
Korea & 66.3 & $(8)$ & 5.9 & $(5)$ & 0.94 & $(5)$ & 0.89 & $(5)$ & 0.89 & $(10)$ \\
Singapore & 380.7 & $(1)$ & 0.8 & $(2)$ & 0.99 & $(2)$ & 0.98 & $(2)$ & 0.99 & $(2)$ \\
Taiwan & 77.2 & $(7)$ & 6.7 & $(6)$ & 0.94 & $(6)$ & 0.88 & $(6)$ & 0.92 & $(7)$ \\
H. K. & 217.4 & $(2)$ & 0.0 & $(1)$ & 1.00 & $(1)$ & 1.00 & $(1)$ & 1.00 & $(1)$ \\
Indonesia & 49.0 & $(10)$ & 7.3 & $(7)$ & 0.93 & $(7)$ & 0.87 & $(7)$ & 0.93 & $(5)$ \\
Malaysia & 160.9 & $(3)$ & 9.8 & $(9)$ & 0.91 & $(9)$ & 0.83 & $(9)$ & 0.90 & $(8)$ \\
Philippines & 102.8 & $(5)$ & 23.5 & $(13)$ & 0.81 & $(13)$ & 0.66 & $(13)$ & 0.68 & $(14)$ \\
Thailand & 93.0 & $(6)$ & 15.4 & $(11)$ & 0.87 & $(11)$ & 0.75 & $(11)$ & 0.87 & $(11)$ \\
China & 46.0 & $(11)$ & 20.2 & $(12)$ & 0.83 & $(12)$ & 0.69 & $(12)$ & 0.70 & $(13)$ \\
Vietnam & 112.4 & $(4)$ & 12.1 & $(10)$ & 0.89 & $(10)$ & 0.80 & $(10)$ & 0.84 & $(12)$ \\
\hline \hline
\end{tabular}

Notes: A: $100 *(\mathrm{X}+\mathrm{M}) / \mathrm{GDP}$, where $\mathrm{X}$ is exports, $\mathrm{M}$ is imports and GDP is Gross Domestic Product in 1995 US\$

$T$ : uniform tariff equivalent $(\%)$

$M_{1}: 1 /(1+0.01 * \mathrm{~T})$

$M_{2}: 1 /(1+0.01 * \mathrm{~T})^{2}$

$N$ : actual $(\mathrm{X}+\mathrm{M}) /$ free trade $(\mathrm{X}+\mathrm{M})$, at base period (actual) prices

na: a positive value for the uniform tariff equivalent could not be obtained for $T$ in the range $0 \%$ to $200 \%$.

Source: Calculated from the GTAP version 4 database. 


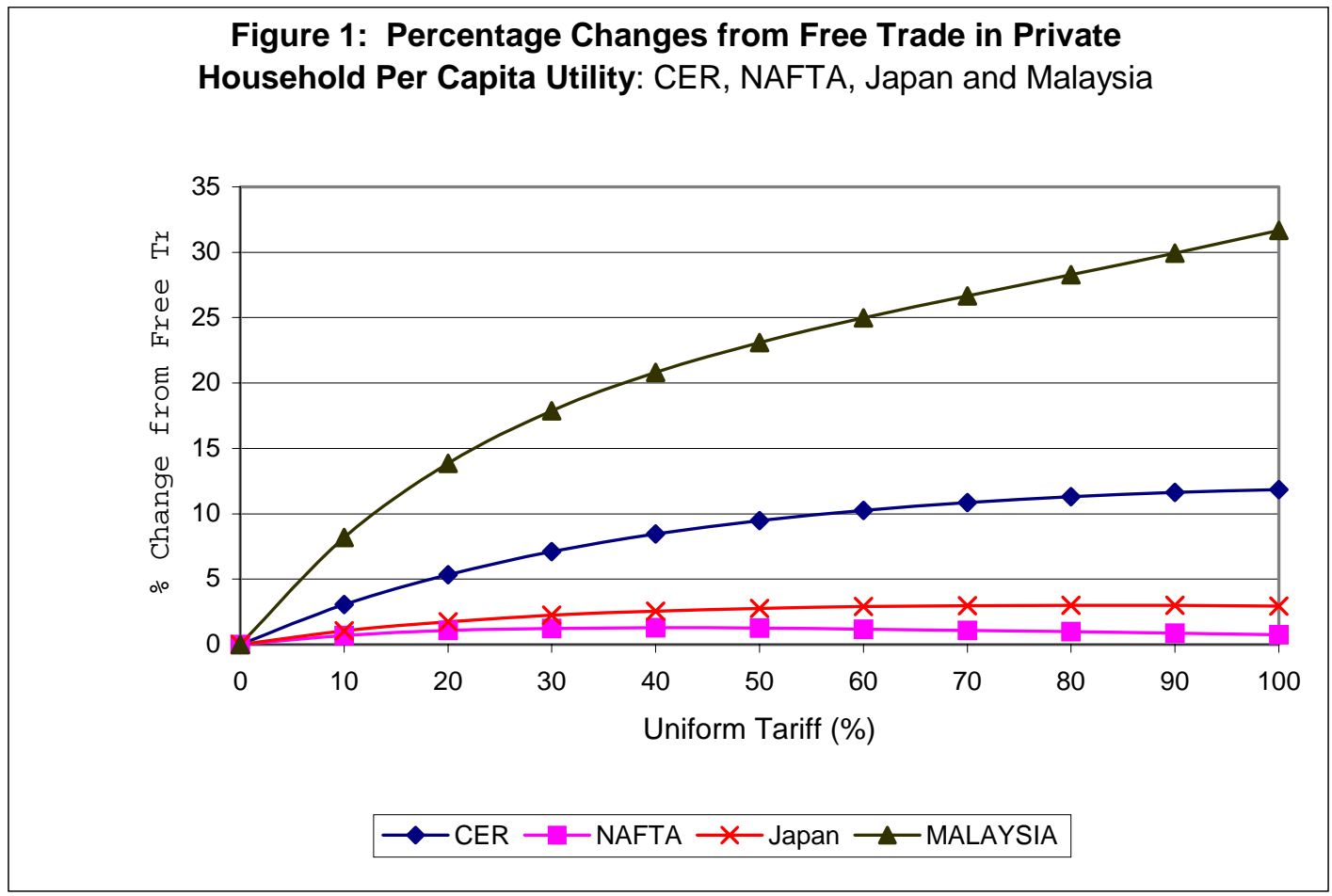

Source: Calculated from the GTAP version 4 database

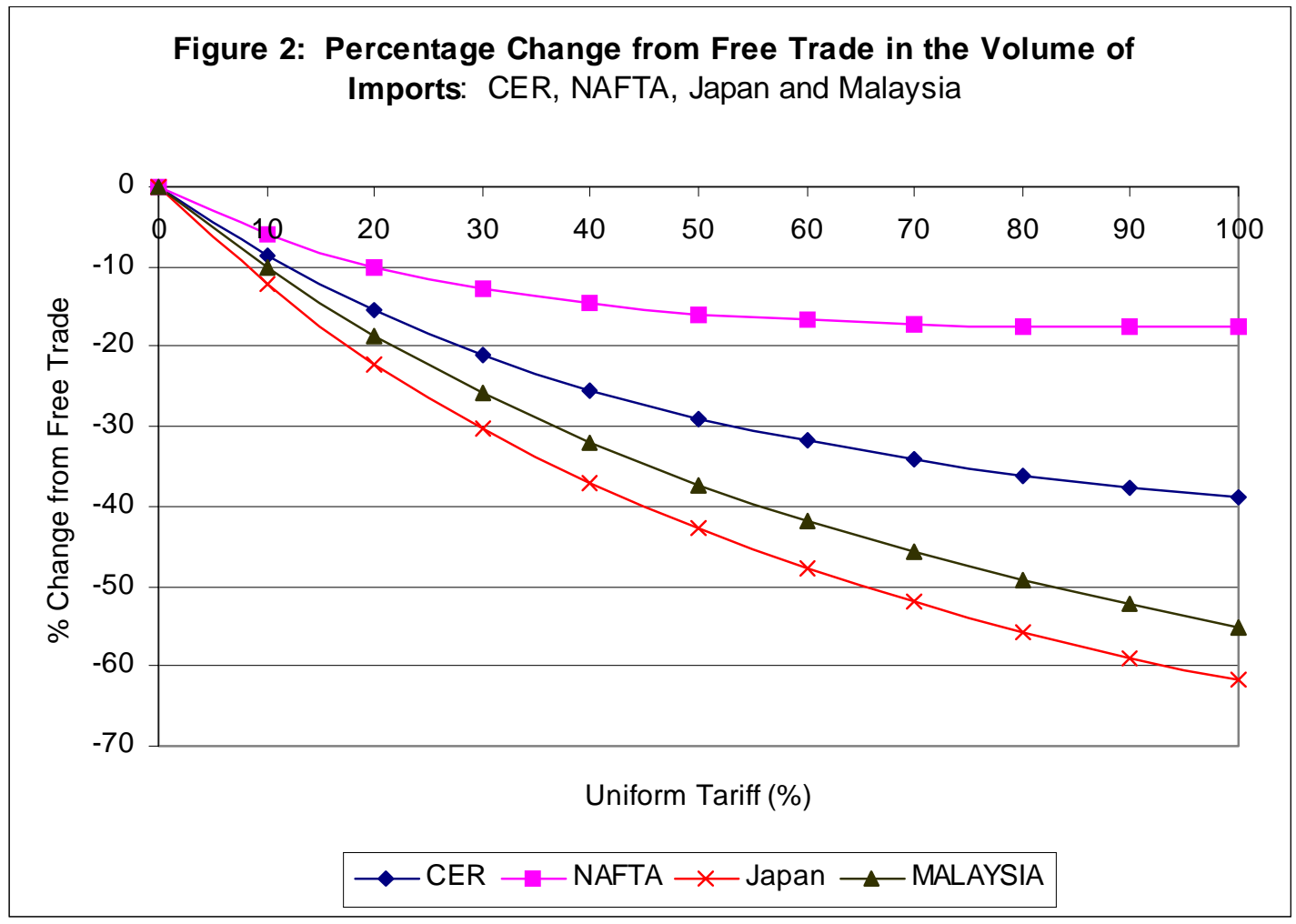

Source: Calculated from the GTAP version 4 database 


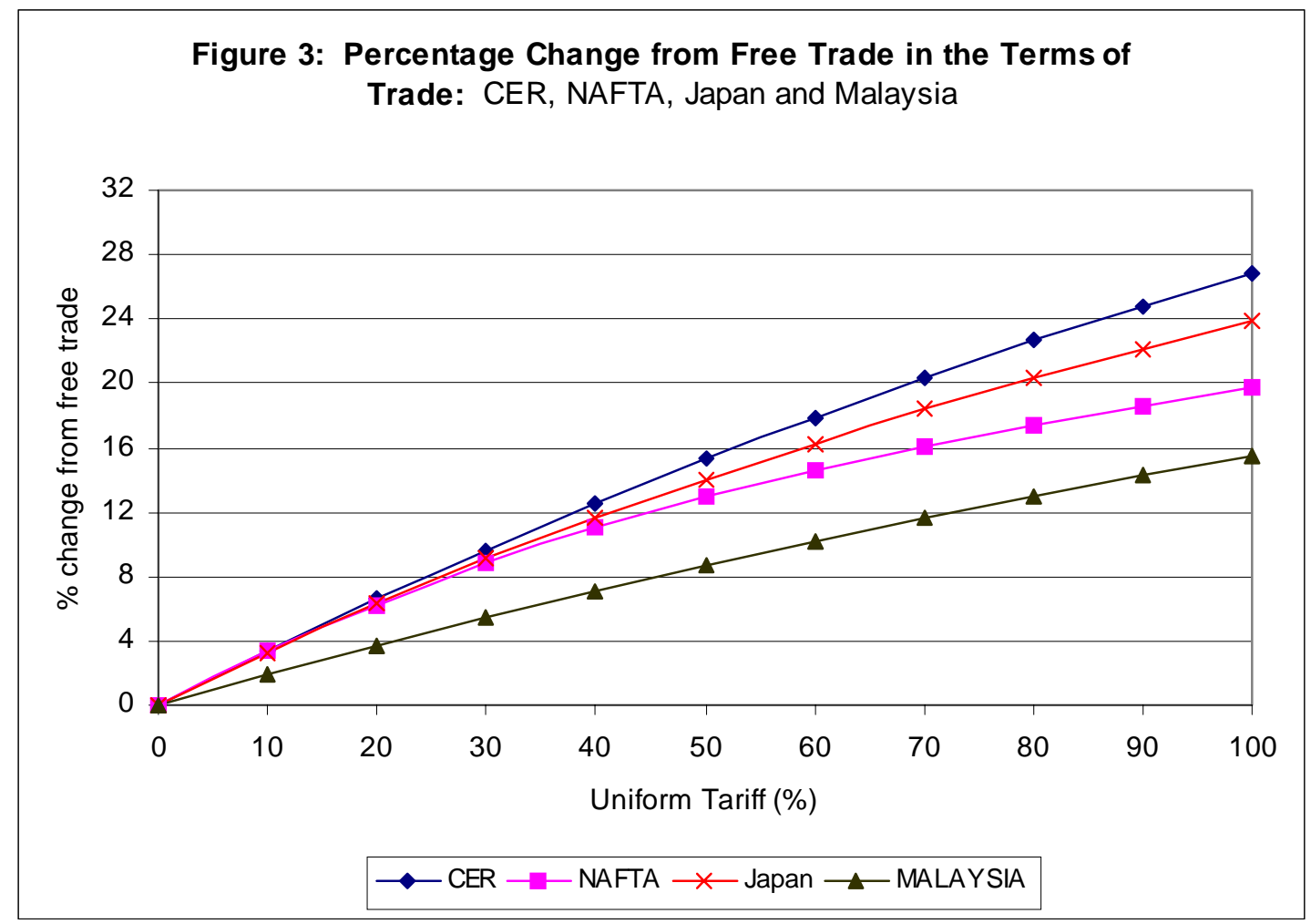

Source: Calculated from the GTAP version 4 database 